\title{
SUSTAINABLE GROUNDWATER RESOURCE MANAGEMENT IN THE THIRAPPANE TANK CASCADE SYSTEM
}

\author{
C. SHANTHI DE SILVA* \\ Department of Agricultural and Plantation Engineering, \\ Faculty of Engineering Technology, \\ The Open University, Nawala, Nugegoda
}

(Received: 16 April 2001 ; accepted: 01 July 2002)

\begin{abstract}
Water shortage is the major problem in small tank cascade systems due to insufficient water storage in the tanks. Because of this, farmers are compelled to dig their own agro-wells near the tank bunds and in the lower command area but they are unable to manage surface and groundwater efficiently to achieve sustainable irrigation. Therefore, the objective of this study was to develop guidelines for efficient use of surface and groundwater. To achieve this, the intermediate objectives were to estimate the aquifer parameters, annual average recharge and to develop a nomograph. The study was done in the Meegassagama tank and the lower command area which is in the Thirappane Tank Cascade System. Seven agro-wells were selected for detailed study and equipped with observation bore holes, rain gauge and evaporation pan. Daily monitoring was done on groundwater level fluctuation, rainfall, evaporation, pumping activity, crop and soil information. Many pumping tests were also conducted and analysed by the radial flow model to estimate the aquifer parameters. Results of the study showed that the average aquifer hydraulic conductivity is $5 \mathrm{~m} /$ day and the specific yield is 0.035 . Annual average recharge for a year of $1897 \mathrm{~mm}$ total rainfall is $170 \mathrm{~mm}$. A nomograph was developed based on the results which could be used to identify the optimum well dimensions in a new agro-well system and /or to identify the sustainable volume of groundwater available for irrigation from a well.
\end{abstract}

Key Words: Agro-well, sustainable irrigation, water shortage, well dimension

\section{INTRODUCTION}

A tank cascade, or a chain of tanks, is a series of small reservoirs that are constructed at successive locations down a single common water course. Any excess water flowing from one tank is captured in the next downstream tank. A tank in the cascade irrigates an area that lies downstream. This irrigated command usually extends right to the edge of the water of the next tank. A cascade, according to the definition of Madduma Bandara ${ }^{10}$ is a "connected series of tanks organised within the micro- catchments of the dry zone landscape, storing, conveying and utilising water from an ephemeral rivulet. Terrain and climate dictate the total quantity of water and irrigated land when the tanks are full". Itakura and Abernethy ${ }^{8}$ describe a tank cascade or a chain of tanks as a series of small reservoirs that are constructed at successive locations down a single common water course. Many studies have been carried out by a number of scientists such as Farmer ${ }^{6}$ and Tennakoon ${ }^{13}$ on the 
concept of small tank cascade systems where the focus was on a single village tank rather than the whole cascade.

Studies reported so far have been conducted on individual small tanks rather than on a whole cascade. The first water balance study to be conducted on a whole cascade was by Itakura. ${ }^{7}$ However this study did not include the groundwater component as it was on surface water balance. Studies on individual aspects such as runoff and rainfall confidence limits have been done by a number of researchers such as Somasiri ${ }^{12}$, Dharmasena ${ }^{5}$, Itakura ${ }^{7}$, Panabokke and Walgama. ${ }^{11}$ No studies have been carried out on a small tank cascade with agro-wells and the problems faced in conjunctive use of surface water and groundwater in such a system. Adetailed survey conducted by the Hector Kobbekaduwa Agrarian Research and Training Center showed that only 30 percent of the farmers cultivate half to one acre. This is because they do not have any idea of the available water in their wells or techniques to optimise the utilization of water. Their survey results also revealed that 90 percent of the farmers do not use water management techniques (Personal communication -Ariyabandu, 2000).

This study was conducted to investigate the efficient use of agro-wells in the small tank systems. Meegassagama, in the Thirappane Tank Cascade System, was selected for this study, because taking the entire cascade into consideration would have masked the individual component's contribution. The overall objective of this study was to analyse the groundwater resource (only the quantity) in the Meegassagama tank cascade by estimating the aquifer parameters, annual average recharge, developing a nomograph to identify the optimum well dimensions and the available groundwater for sustainable irrigation.

\section{METHODS AND MATERIALS}

Thirappane is about $30 \mathrm{~km}$ south of Anuradhapura. This area consists of six connected tanks and their respective command areas ranging along a small water course, which finally connects to the Nachchaduwa Reservoir. The complete system of tanks and their command areas is about $8 \mathrm{~km}$ in overall length and $2 \mathrm{~km}$ wide. The main cascade as shown in Figure 1 consists of the tanks of Venrarankulama, Meegassagama, Alisthana and Thirappane.

The Meegassagama lower command area was considered for t'ie detailed study (Figure 2). The catchment area of the Meegassagama tank is $3.56 \mathrm{~km}^{2}$. In general, a considerable part of the catchment is covered in forest, but it is often said that the proportion of forest has been gradually diminishing under the pressure of extensive shifting cultivation and deforestation. The Meegassagama tank sluice level is $3 \mathrm{~m}$ in height and has an effective capacity of $36 \times 10^{4} \mathrm{~m}^{3}$. During the Maha or wet season, in October or November, irrigated rice fields are predominant in this area when compared with other upland field crops, such as chilli, soybean, ladies' fingers, etc. 
On the other hand, in the Yala or dry season, the irrigated rice area is reduced sharply due to a serious water shortage. Consequently, the ratio of the other crops to rice increases relatively during Yala. On the whole, the proportion of cash crops has been increasing year by year with the increase of privately owned agro-wells. To avoid over- exploitation of the groundwater resource, there is an urgent need to identify the optimum well dimension such as well spacing, depth and radius based on aquifer properties, recharge and the other scientific aspects for sustainable irrigation.

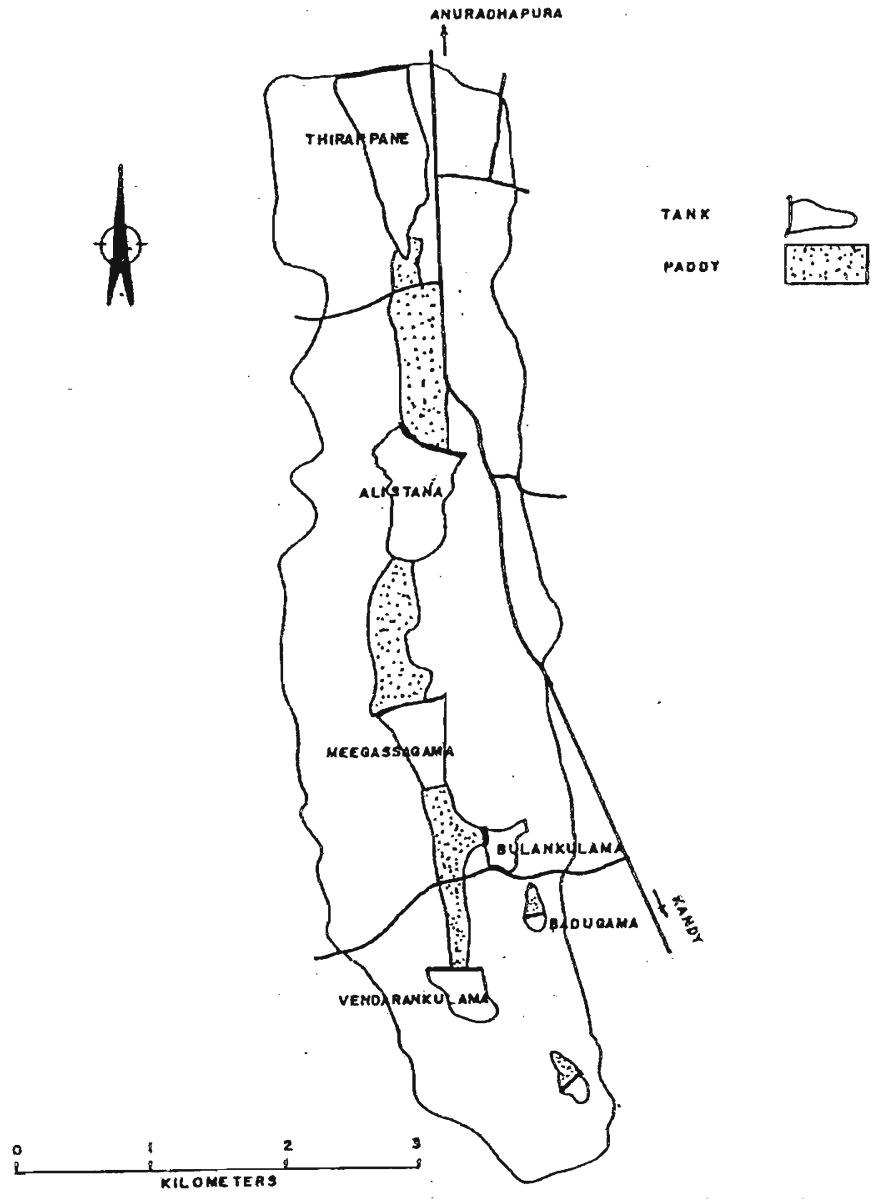

Figure 1: Thirappane Tank Cascade System

Seven agro-wells in the lower command area of the Meegassagama tank were selected and 20 observation bore holes were drilled (Figure 2). This site was equipped with a rain gauge and an evaporation pan. Daily monitoring was done on groundwater levels in the seven agro-wells and twenty observation bore holes before and after pumping, abstraction, rainfall and evaporation. In addition, crop 
information on the type of crop grown, extent of cultivation, irrigation interval, amount of irrigation and other supplementary data were recorded periodically.

\section{COMMAND AREA OF THE MEEGASSAGAMA TANK \\ ALISTHANA TANK}

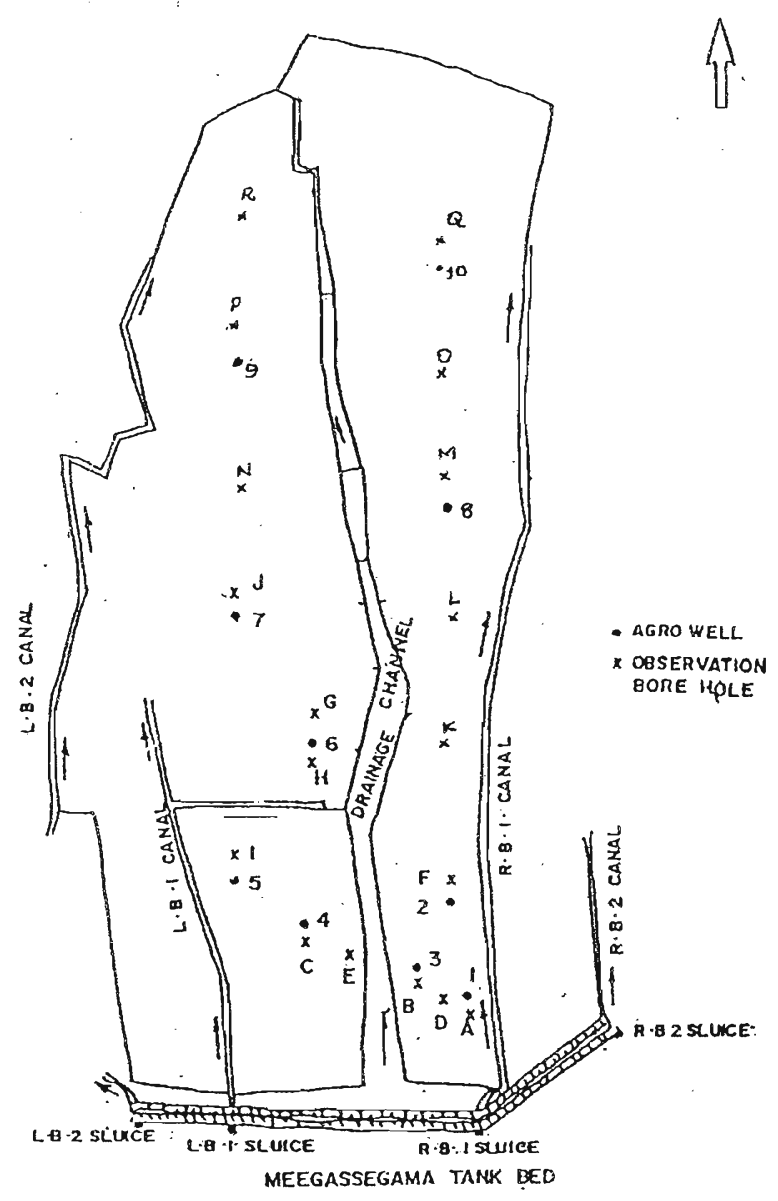

Figure 2: The study area in the Meegassagama tank command area

Additional data on outflow, tank water issue, seepage from tank and topographical survey were collected from the International Irrigation Management Institute (IIMI). Outflow of the area was measured daily by a flume installed at the outlet. Seepage from the tank was estimated using the catchment water balance study. Climatological data was collected from the Meteorological Station. Many pumping tests were carried out during the study period. 


\section{RESULTS AND DISCUSSION}

The results discussed were based on the data collected from February 1997 to October 1998. The analysis was done mainly using the methodology and the radial flow model already developed. ${ }^{1}$ The radial flow model was used to interpret the behaviour of larger diameter wells in the hard rock aquifer of Sri Lanka. ${ }^{2}$ The same model was used after calibration to develop nomographs for Kobeigana in the Kurunegala District $^{3}$ and Huruluwewa in the Anuradhapura District. ${ }^{4}$

Aquifer flow mechanisms: Aquifer flow mechanisms are discussed under aquifer parameters and aquifer flows. Aquifer parameters indicate the ability of the aquifer to store and transmit water. Aquifer flows of the wells will show how the aquifer behaves during the pumping and recovery phases.

Aquifer parameters: Pumping tests were analysed using the radial flow model. ${ }^{1}$ The model results were compared with the draw down and the discharge from the aquifer in the pumped well and observation bore hole draw down at $10 \mathrm{~m}$ and $30 \mathrm{~m}$ from the well center. A range of parameter values was tried and a satisfactory agreement between the field and model results was obtained (Figure 3). The hydraulic conductivity varied from $7 \mathrm{~m} / \mathrm{d}$ to $3.5 \mathrm{~m} / \mathrm{d}$ on average. It indicates that the lower command area is associated with varying aquifer parameters. If the wells were constructed based on scientific research, these locations would have been avoided for the construction of wells.

Aquifer flows: Aquifer flows were analysed during the pumping and recovery phase by a simulation model after a satisfactory agreement with the simulated and field results on draw down and discharge (Figure 3). When the aquifer flow in a particular well was compared during the late dry season (October '97 and '98) and early dry season (April '97 and '98), it showed that the aquifer flow during the early dry season was higher than that in the late dry season. This may be due to the fact that during the early dry season the aquifer water level was high $(0.5 \mathrm{~m}-1 \mathrm{~m}$ below ground level), and the abstraction in the well, which creates the higher groundwater table gradient. Therefore, the flow into the well was high during the early dry season after pumping. During the late dry season, the aquifer water level was low ( $2 \mathrm{~m}$ - $3 \mathrm{~m}$ below ground level) and the groundwater table gradient was shallow after pumping, therefore, the aquifer flows were less during the late dry season.

Annual average recharge: The objective of this section is to estimate the average annual recharge for a typical land use or cropping pattern adopted in the Meegassagama area. Many methods of estimating recharge have been reported in the literature. However, the rate of aquifer recharge is not only the most difficult and uncertain factor to measure but it also exhibits high spatial and temporal variability and process non-linearity. Therefore, there is no established methodology to satisfactorily estimate recharge. In this study, the soil moisture balance method 
was used. The reason for the selection of the soil moisture balance method for estimation of recharge is discussed below.

Physical methods of estimating aquifer recharge consists of (i) soil physical measurements as the hydraulic or Darcian approach (ii) groundwater level fluctuation method and (iii) soil moisture balance. The hydraulic approach based on Darcy's equation of recharge estimation offers the most direct measurement of seepage rates and average recharge. This method involves the regular monitoring of recharge over a period of several years. This is most laborious and expensive and requires field equipment and personnel. It is site specific. In the groundwater level fluctuation method, the specific yield is used to transform a change in groundwater level to an equivalent amount of recharge. This method can give information on temporal and areal recharge variations. However, this method can be misleading if the water level fluctuation is confused with those resulting from pumping or other causes.

In the soil moisture balance method, a daily estimate of the soil moisture balance is made with an input of precipitation plus irrigation (tank issue) minus run-off and losses due to actual evapotranspiration and drainage which includes aquifer recharge. When the soil moisture deficit is zero, water can pass through the soil to the aquifer, provided the aquifer can accept the water. This conventional soil moisture balance technique gives an acceptable estimate of the recharge, if the ground is flat. The soil zone is in direct contact with the aquifer, if the hydraulic conductivity of the aquifer is high and the water table is some distance below the top of the aquifer. However, large errors could occur unless the accounting period for the soil water balance is less than 10 days. This is because short periods of recharge are often not accounted for, which give an averaging effect on monthly input data. The advantage of obtaining a realistic soil moisture balance is the estimation of actual evapotranspiration with the variation of recharge.

Groundwater level fluctuation, abstraction and rainfall: Groundwater level fluctuations were monitored in twenty observation bore hole locations in the study area from February 1997 to October 1998. All the groundwater level measurements were recorded as depths in metres below ground level (mbgl).

The year 1997 had received a total rainfall of $1897.2 \mathrm{~mm}$ and a higher amount of rainfall was observed from March to May and then again from September to December (Table 1). Groundwater fluctuation also followed a similar pattern with rainfall. The groundwater levels were high (less than $1 \mathrm{mbgl}$ ) during March, April and May. The groundwater level rose to ground level in early November after the heavy rainfall in September and October. After November the excess rainfall was lost as runoff because the aquifer was full and unable to hold any more water as was indicated by the high groundwater level in the aquifer. During the year 1997, 
farmers used their agro- wells for irrigation from the end of May until the end of September.

The total rainfall during the year 1998 was $1018 \mathrm{~mm}$, which was only 53\% of the total rainfall received during 1997. But the 1998 rainfall was better distributed over the 12 months rather than concentrated in a few months. The groundwater level was very shallow during the year 1998. In low lying areas there were water logged patches. A maximum groundwater level drop of $1.25 \mathrm{mbgl}$ was observed in October 1998. During the year 1998, farmers cultivated only paddy and not other field crops.

Out of twenty observations of bore hole data and groundwater levels, two observation bore holes were selected to show the variations as they represent the field situation very clearly (Figure 4). It is clear from the figures that there were two prominent rainy seasons during the year 1997 in the study area. As a result there were two prominent rises of groundwater levels indicating the aquifer recharge. The first groundwater level rise of $2.05 \mathrm{~m}$ was observed from 15 March to 15 May. The second groundwater level rise of $2.3 \mathrm{~m}$ was jbserved from 30 September to 15 November.

Table 1: Rainfall, groundwater levels and abstraction pattern in the study area

\begin{tabular}{lrrrrrr}
\hline Month & \multicolumn{2}{c}{ Rainfall $(\mathrm{mm})$} & \multicolumn{2}{c}{ Groundwater level (mbgl) } & \multicolumn{2}{c}{ Abstraction (m ${ }^{3} /$ day) } \\
& 1997 & 1998 & 1997 & 1998 & 1997 & 1998 \\
\hline January & 9.0 & 141.3 & - & 0.0 & 40.3 & 0 \\
February & 13.2 & 0.0 & 1.75 & 0.0 & 48.1 & 0 \\
March & 29.4 & 15.2 & 2.52 & 0.4 & 51.4 & 0 \\
April & 202.8 & 129.2 & 2.43 & 0.5 & 0.0 & 0 \\
May & 186.1 & 142.6 & 0.8 & 0.4 & 1.8 & 0 \\
June & 12.4 & 1.2 & 1.35 & 0.55 & 23.8 & 0 \\
July & 27.2 & 59.6 & 1.64 & 0.64 & 23.8 & 0 \\
August & 1.6 & 74.1 & 2.2 & 0.7 & 25.3 & 0 \\
September & 141.6 & 55.8 & 2.3 & 1.0 & 1.8 & 0 \\
October & 399.8 & 52.3 & 2.2 & 1.25 & 0.0 & 0 \\
November & 503.8 & 161.0 & 0.5 & 0.4 & 0.0 & 0 \\
December & 370.0 & 185.7 & 0.0 & 0.0 & 0.0 & 0 \\
TOTAL & 1897.2 & 1018 & & & & \\
\hline
\end{tabular}


Estimation of recharge in the project area: For this project, the Irrigation Water Requirement (IWR) computer prediction model ${ }^{9}$ was used to estimate the actual recharge for a typical cropping pattern in the project area. The IWR computer model simulates a soil moisture balance. This program uses a two layered soil water balance model to estimate the changes in water content of two layers on a daily basis taking into account inputs of rainfall and tank issue (only a part of the total tank water issue) and outputs of evapotranspiration (modified for the crop cover of the shallow rooted vegetation and soil water status) and deep drainage (actual recharge to groundwater). It is assumed that water can flow through the soil to the aquifer only when the moisture deficit is zero.

The model combines information on the type of crop grown (dates of planting, emergence, $20 \%$ cover, maturity and harvest), soil characteristics (field capacity as $328 \mathrm{~mm}$ and permanent wilting point as $178 \mathrm{~mm}$ ) and reference crop evapotranspiration at the site, to estimate daily water use. This was combined with daily rainfall data and the tank issue (a part of the total tank issue) in the water balance to calculate a daily soil water deficit.

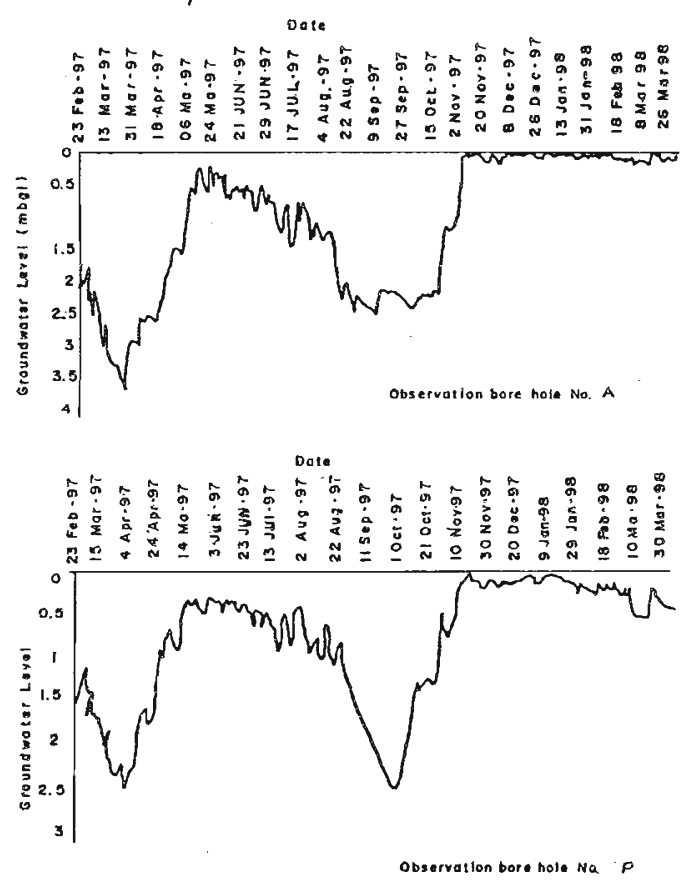

Figure 3 : Groundwater level fluctuation in two observation bore holes

The IWR model was initially run with the field data collected for the year 1997. The model was run from January to December. The soil moisture deficit on 1 January was taken as zero because the soil was fully saturated. The model was 
used to simulate the actual recharge. The simulated actual recharge was compared with the recharge estimated from the groundwater level rise and specific yield estimated in the section of aquifer flow mechanisms. The estimated average annual recharge was $170 \mathrm{~mm}$ for the year 1997. This estimation agrees with the annual average recharge calculated for the Huruluwewa catchment in Anuradhapura.

Development of a Nomograph: In developing the nomograph, simulation of groundwater abstractions was carried out by the radial flow model after calibrating for long term behaviour. A growing season of 210 days from February to September was taken as an example to calibrate the long term behaviour of the aquifer in the Meegassagama lower command area. It is assumed that the wells fully penetrate the aquifer, therefore the well depth is equal to the aquifer depth and the aquifer is fully recharged. The maximum pumped draw down in the model was set as $90 \%$ of the saturated depth so that there would always be $10 \%$ of the saturated depth of the water at the bottom of the well. When this draw down was reached in the simulation, the pump was automatically switched off and the well supply was regarded as having failed. The hydraulic conductivity ( $5 \mathrm{~m} /$ day) and specific yield $(0.035)$ of the study area were used for the simulation exercise. No flow boundary condition was imposed at the radial distance of $105 \mathrm{~m}$ from the well center assuming the wells were at least at $200 \mathrm{~m}$ spacing. Since the slope of the study area was less than $5 \%$, the radial flow model could be used without significant error.

Well radii from $1 \mathrm{~m}$ to $6 \mathrm{~m}$ at intervals of $1 \mathrm{~m}$ and well depths from 4 to $10 \mathrm{~m}$ at intervals of $1 \mathrm{~m}$ were tested for three spacings between wells. Results obtained were developed into a nomograph shown in Figure 4. The nomograph gives the interrelationships among the well radius, well depth and well spacing, maximum abstraction, and sustainable abstraction per season. Sustainable well yield is the volume of water that can be extracted safely without interfering with neighbouring wells. It is important that for sustainability of well pumping over a continued period, the total maximum abstraction should not exceed the total recharge per year.

Use of the nomograph: The nomograph can be used in a number of ways. One is to identify the optimum well dimensions for a new agro-well system and the second is to identify the sustainable yield of a well in an existing agro-well system.

In a new agro- well system, based on the farmer population and the available aquifer area, it is possible to identify the optimum well depth, radius and spacing from the nomograph. It is advisable to choose a 3-4 m radius well of $6 \mathrm{~m}$ depth with $200 \mathrm{~m}$ spacing. In an existing agro- well system, identify the sustainable volume of water that could be used for a season from the nomograph for a particular well dimension existing in the field. For example, if an agro- well of $6 \mathrm{~m}$ depth and $3 \mathrm{~m}$ radius with the average spacing between two adjacent wells of $100 \mathrm{~m}$ is considered, the average recharge to the aquifer is $170 \mathrm{~mm}$ and the area associated with the well at $100 \mathrm{~m}$ spacing is about $10000 \mathrm{~m}^{2}$. Therefore, the recharge available per well 
is $1700 \mathrm{~m}^{3}$. According to the nomograph, the maximum volume of water that could be abstracted from the well is $4200 \mathrm{~m}^{3}$. The sustainable volume of water is only $1700 \mathrm{~m}^{3}$. If this limit is exceeded, there will be over exploitation of the groundwater resource. In addition, if the farmer is abstracting only $1700 \mathrm{~m}^{3}$ per growing season, then a well of $1.5 \mathrm{~m}$ radius is more than enough to supply the same volume of water. Similarly, this nomograph could be used to estimate the available groundwater resource for irrigation after calculating the average recharge for that year. By this, it could be possible to include the recharge variation over the years. It could be done by getting the sustainable water yield of a particular well radius and depth at a fixed well spacing multiplied by the number of wells in the lower command area of the tank. After learning the sustainable volume of water that could be used for irrigation from the individual well, a farmer could keep a record on his abstraction over the season. If he exceeds the amount in one season, he could use the water efficiently or reduce the extent of land cultivated during the next season. Therefore, by having this nomograph, farmers could manage their own wells to ensure a successful cultivation.

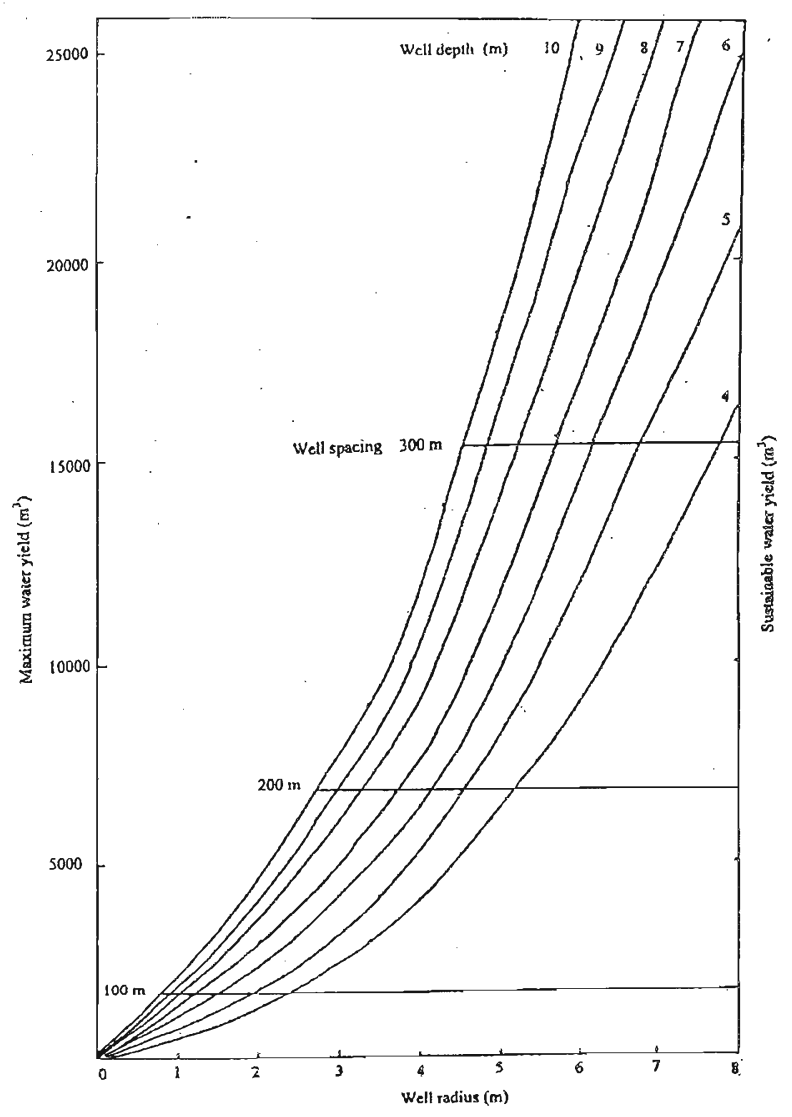

Figure 4: The Nomograph 


\section{CONCLUSIONS}

This study indicates that surface and groundwater resources are interrelated. The estimation of groundwater resource needs detailed field data with a high degree of accuracy.

Aquifer parameters were estimated by analysing pumping data using the radial flow model. The hydraulic conductivity varies from $2 \mathrm{~m} /$ day to $5 \mathrm{~m} /$ day. It shows that there are some patches of aquifer with low hydraulic conductivity. On an average, the hydraulic conductivity is $5 \mathrm{~m} /$ day and the specific yield is 0.035 .

Soil moisture balance estimated the actual recharge using the weather, crop and soil data. Accordingly, the average annual recharge for the year 1997 was $170 \mathrm{~mm}$. Recharge will vary according to the total rainfall and its distribution. Agro-wells are used extensively to abstract groundwater in the lower command area of the Meegassagama tank. The nomograph developed in this study could be used to identify the optimum well dimension for a well in a new agro-well system and the sustainable volume of water for irrigation for a well of predetermined dimension in an existing agro-well system after estimating the recharge for that particular year.

\section{Recommendations}

* Similar studies to develop nomographs have to be undertaken in areas where agro- wells are being intensively used.

* Based on the nomograph, the optimum well dimension should be identified and strictly adhered to in constructing new agro-wells.

* Where well dimension is fixed in existing agro-well systems, the sustainable volume of water for irrigation could be determined from the nomograph. It must be adhered to by keeping regular records of abstraction by the farmers.

\section{Acknowledgement}

The author gratefully acknowledges the financial support given by the National Science Foundation (Research grant -RG/01/AG/97). Thanks are due to Mr MM Jayathileke of the Department of Civil Engineering for collecting data and performing pumping tests in the study area.

\section{References}

1 De Silva C.S (1995). Use of large diameter wells for supplementary irrigation in the hard rock aquifers of Sri Lanka, Ph.D thesis unpublished. Silsoe College, Cranfield University, United Kingdom. 
2 De Silva C.S \& Rushton K.R (1996). Interpretation of the behaviour of agrowell systems in Sri Lanka using radial flow models. Journal of Hydrological Sciences. 41(6): 825-835.

3 De Silva C. S (1997). Groundwater regulation through design of agro-well dimensions in the North-Western Province of Sri Lanka. Journal of Tropical Agricultural Research, 9:288-301.

4 De Silva C.S., Fernando N., Sakthivadivel R. \& Merry D. (1998). Managing groundwater in hard-rock areas through agro- well design and development. Journal of Water Resources Development, Vol. 15. No 3: 333-348.

5 Dharmasena P.B (1991). Present use of land and water resource in village tank farming, Journal of Soil Sciences Society of Sri Lanka. 7:7-17.

6 Farmer B.H (1957). Pioneer peasant colonization in Ceylon. London, U.K: Oxford University Press.

7 Itakura J. (1994). Water balance model for reform planning of tank cascade in irrigation systems in Sri Lanka. Unpublished report.

8 Itakura J \& Abernethy C. (1993). Water management in a tank cascade in irrigation systems in Sri Lanka: First seasonal report of TARC-IIMI Joint Project 1991/1992. Maha Season. Colombo, Sri Lanka:Working paper No 24.

9 Hess T. (1990). Balance: A soil water balance programme. Silsoe College, Cranfield University, UK.

10 Madduma Bandara C.M (1985). Catchment ecosystems and village tank cascades in the dry zone of Sri Lanka. In J. Lundqvist, U, Lohm and Falkernmark, (Eds) Strategies for River Basin Development, Germany Reidel Publishing Company, pp 99-113.

11 Panabokke C.R \& Walgama A. (1974). The application of rainfall confidence limits to agriculture in the Dry Zone of Sri Lanka. Journal of National Science Council of Sri Lanka Sri Lanka 2(2): 95-113.

12 Somasiri S. (1992). Water conservation in small and medium sized tanks for agriculture. Tropical Agriculturist, 135:33-46.

13 Tennakoon M. U. A. (1974). Rural settlement and land use in North Central Sri Lanka. Thesis presented to the Department of Geography, Syracuse, NY, USA. 